\title{
Diagnostic Accuracy of Doppler Ultrasonography for Diagnosis of Epididymo-Orchitis in Patients presenting with Scrotal Swelling
}

\author{
JAWAD ALI MEMON ${ }^{1}$, ADNAN AHMED ${ }^{2}$, MUMTAZ AHMED QURESHI ${ }^{3}$, HAFEEZ UR REHMAN ${ }^{4}$, TAHIR BAIG ${ }^{5}$, \\ RABIA SHAH \\ ${ }^{1}$ Assistant Professor Radiology, People's University of Medical and Health Sciences for Women (PUMHSW. SBA) \\ ${ }^{2}$ Associate Professor Radiology, Liaquat University of Medical and Health Sciences, Jamshoro \\ ${ }^{3}$ Assistant Professor Pediatric Surgery Liaquat University of Medical \& Health Sciences, Jamshoro. \\ ${ }^{4}$ Senior Registrar Radiology department, Gajju Khan Medical College, Swabi \\ ${ }^{5}$ Assistant Professor Radiology, Rai Medical College, Sargodha \\ ${ }^{6}$ Medical Officer, FCPS Diagnostic Radiology,SPR HMC Radiology Peshawar. \\ Corresponding author: Dr. Jawad Ali Memon, Email: Jawad nimra@yahoo.com, Cell No: +923337011947
}

\begin{abstract}
Background and Aims: Epididymitis, orchitis, testicular torsion and appendix testis torsion causes most common and acute scrotal pain. The scrotal pain and complications could be diagnosed with Doppler ultrasound and histopathology post-surgery procedures. The current study aims to determine diagnostic accuracy of Doppler Ultrasonography for diagnosis of epididymis-orchitis in patients presenting with Scrotal Swelling.

Materials and Methods: This cross-sectional study was carried out on 121 scrotal masses patients during the period from April 2020 to September 2020 at the radiology department ofLiaquat University of Medical and Health Sciences, Jamshoro. Individuals who met the inclusive criteria were enrolled and consent form was taken from each patient. The patient's age range was 15 to 68 years old with mean \pm SD $34.5 \pm 12.4$. All the patients were presented with scrotal swelling. After history taken from the individual, Doppler ultrasound (DUS) was conducted. The final outcomes were compared by radiologist and surgeon. All the patients were subjected to linear transducer and Toshiba Xario 200 with 11MHZ. Diagnostic accuracy of Doppler ultrasound was calculated from the sensitivity and specificity.

Results: Doppler ultrasound diagnosed allthe epididymitis and orchitis, testicular torsion, hydrocele, spermatic cordinjury, and varicocele cases with specificity and sensitivity $100 \%$. The frequency of finally diagnoses performed by Doppler ultrasonography was orchitis (7), epididymitis-orchitis (45), testicular malignancy (15), spinal cord injuries(3), testicular torsion (5), hematocele (3), spermatic cord injuries (2),varicocele (14), hydrocele (25), and pyocele (2). Out of 15 testicular subjectsdiagnosed on DUS, only 14 were found to have malignancy. Two cases ofOrchitis were diagnosed falsely as amalignancy. In Orchitis 7 patients, 6 were diagnosed as orchitis but one hadseminoma (specificity $67 \%$ and sensitivity $88 \%$ ). The overall DUS specificity andsensitivity were $67 \%$ and $98 \%$ respectively.

Conclusion: The scrotal disease can be diagnosed with effective, reliable, and safe Doppler Ultrasonography. Testicular tumor diagnosis is an additional advantage of DUS besides minimizing unnecessary exploration operations numbers. Doppler ultrasonographyplays a vital role in need of immediate diagnosis of testicular torsion.

Keywords: Doppler ultrasound scan, Scrotal pathologies, Epididymo-Orchitis
\end{abstract}

\section{INTRODUCTION}

Scrotum acute painful swelling with general symptoms and signs accompanied by its content is referred to as acute scrotum [1]. Most scrotum patients are unaware of the symptoms due to lack of patient negligence about the disease until it becomes severe, painful, and examined physically. The proportion of scrotal problems and testicular problems account for $3.7 \%$ in surgical operation in children due to testicular appendage torsion causing acute scrotal pain. The epididymitis pain becomes severe gradually as the infection starts growing and acute pain rises. The risk factors for testicular torsion are independent of the manifestation of left side pain and its duration [2]. Upon testicular pain diagnosis, immediate surgery needs to be done. Acute scrotal pain is also the most difficult condition to treat in the urological emergency department because it mimics urological symptoms. The major challenge is the scrotal masses differentiation in between the extra and intra testicular mass. For better diagnosis, the presence of mass is needed to be verified. Extra testicular and intra testicular are benign and malignant lesions respectively in most of the scrotal mass cases [3-5]. Scrotal swelling caused either by an extra mass attached to the testicular scrotum or arise from the testicle is difficult to decide based on physical examination. Radiology imaging modality was the preferred evaluation tool for scrotal pain and swelling. Vasculature affected by abnormalities was diagnosed and detected by Doppler ultrasound [6]. Scrotal swelling can be caused by a variety of medical conditions, ranging from benign congenital conditions to life-threatening malignancies and acute surgical emergencies. Finally, surgical exploration confirms the ultrasonography finding. Dilemma diagnosed in most of the cases are due to testicular swelling [7-8].

Testicular perfusion can be evaluated with excellent anatomical details taken by power and color Doppler ultrasonography [9]. Color Doppler ultrasonography is the preferred imaging technique or modalities in scrotal lesions diagnosis. The lesion's characteristics as either extra testicular or testicular along with perfusion and flow can be 
evaluated by Gray-scale ultrasonography, power, and color Doppler respectively [10-12]. In differentiating testicular inflammatory conditions from testicular ischemic, Color Doppler prevents unnecessary surgical intervention and saves time. Testicular malignancy's vascular condition can be assessed with color Doppler higher specificity and sensitivity [13]. Doppler ultrasonography is an effective, safe, and reliable imaging tool for varicoceles lesions and scrotum diseases [14]. Scrotal swelling could be either acute or non-acute. Torsion, abscess, orchitis, and trauma are the acute scrotal swelling while scrotal hernia, hydrocele, and lymphocele are non-acute one. Testicular lesions include inflammatory conditions, trauma, neoplasms, and torsion. The epididymis, scrotal wall, and spermatic cord are the extra testicular lesions. Doppler ultrasonography plays a vital role in differentiating these two abnormalities [15]. The current study was carried out to find the accuracy of Doppler ultrasonography in the diagnosis of scrotal masses and their proper management. Doppler ultrasonography was used for perfusion and flow due to availability, painless, non-invasive, and hazard-free radiations.

\section{MATERIALS AND METHODS}

This cross-sectional study was carried out on 121 scrotal masses patients during the period from April 2020 to September 2020 at the radiology department of Liaquat University of Medical and Health Sciences, Jamshoro. Individuals who met the inclusive criteria were enrolled and consent form was taken from each patient. The patients' age range was 15 to 68 years old with mean \pm SD $34.5 \pm$ 12.4. All the patients were presented with scrotal swelling. After history taken from the individual, Doppler ultrasound (DUS) was conducted. The final outcomes were compared by radiologist and surgeon. All the patients were subjected to linear transducer and Toshiba Xario 200 with $11 \mathrm{MHZ}$. Diagnostic accuracy of Doppler ultrasound was calculated from the sensitivity and specificity. Patients who were undescended testis and inguinoscrotal hernia were excluded. The patients with an age range 15 to 68 years and had scrotal pathologies were included. Prior to conducting Doppler ultrasonography, history and physical examination were taken. Transverse images of patients were taken using a multi-frequency transducer $(7-9 \mathrm{MHz})$ Toshiba Xario 200 ultrasound machine. Valsalva maneuvers performed on patients in upright positions were viewed with oblique and coronal planes. Doppler ultrasonography diagnostic accuracy was measured with clinical outcomes (+ve response), histopathological examination results, fine needle aspiration cytology (FNAC), and operative findings. Testis size, echogenicity, and location were found with the help of Doppler ultrasound. Blood flow documentation, velocity flow, test indices, the pattern of the spectral waveform, scrotal scans, and extra and intra-testicular blood vessels were assessed by Doppler ultrasonography. DUS protocol was followed by different radiologists to get the scan images of scrotal swelling. Data analysis and evaluation were done with SPSS version 20. Specificity, negative predictive value, positive predictive value, and sensitivity were calculated using a contingency table.

\section{RESULTS}

The non-probability consecutive sampling technique was used for data collection from Jan 2021 to August 2021. In this study, patients mean age \pm SD was $34.5 \pm 12.4$ years with a range of 15-68 years. The age-wise distribution of 121 patients was as follows; 48 (39.7\%) 15-30 years, 29 (23.9\%) $31-40$ years, 26 (21.5\%) $41-50$ years and 18 (14.9\%) 51-68 years as shown in Figure 1 and Table 1. Higher frequency and percentage of scrotal lymphoma were reported in patients with the disease a condition present in it while large cell orchitis lymphoma mass was with lower frequency and percentage. Most of the patients were in the range of 15 to 30 years. Doppler ultrasound diagnosed all the epididymitis and orchitis, testicular torsion, hydrocele, spermatic cord injury, and varicocele cases with specificity and sensitivity $100 \%$. The frequency of finally diagnosed of Doppler ultrasonography was orchitis (7),epididymitis-orchitis (45), testicular malignancy (15), spinal cord injuries(3), testicular torsion (5), hematocele (3), spermatic cord injuries (2), varicocele (14), hydrocele (25), and pyocele (2) as shown Table 2 and Figure 2. Out of 15 testicular subjects diagnosed on DUS, only 14 were found to have malignancy. Two cases of Orchitis were diagnosed falsely as a malignancy. In Orchitis 7 patients, 6 were diagnosed as orchitis but one had seminoma (specificity $67 \%$ and sensitivity $88 \%$ ). The overall DUS specificity and sensitivity were $67 \%$ and $98 \%$ respectively.

Table 1. Histopathology age group

\begin{tabular}{|l|l|l|}
\hline Age group (Years) & Frequency $(\mathrm{n})$ & Percentage $(\%)$ \\
\hline $15-30$ & 48 & 39.7 \\
\hline $31-40$ & 29 & 23.9 \\
\hline $41-50$ & 26 & 21.5 \\
\hline $51-68$ & 18 & 14.9 \\
\hline Total & 121 & 100 \\
\hline
\end{tabular}

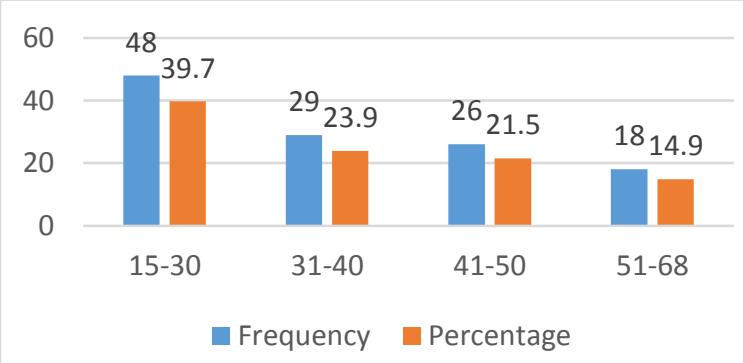

Figure 1. Age group by histopathology

Table 2. Frequency of Scrotal masses

\begin{tabular}{|l|l|l|}
\hline Parameters & Frequency $(\mathrm{n})$ & Percentage $(\%)$ \\
\hline Orchitis & 7 & 5.78 \\
\hline Epididymitis-orchitis & 45 & 37.1 \\
\hline Testicular malignancy & 15 & 12.4 \\
\hline Spinal cord injuries & 3 & 2.4 \\
\hline Testicular torsion & 5 & 4.1 \\
\hline Hematocele & 3 & 2.4 \\
\hline Spermatic cord injuries & 2 & 1.6 \\
\hline Varicocele & 25 & 20.7 \\
\hline Pyocele & 2 & 1.6 \\
\hline Varicocele & 14 & 11.92 \\
\hline Total & 121 & 100 \\
\hline
\end{tabular}




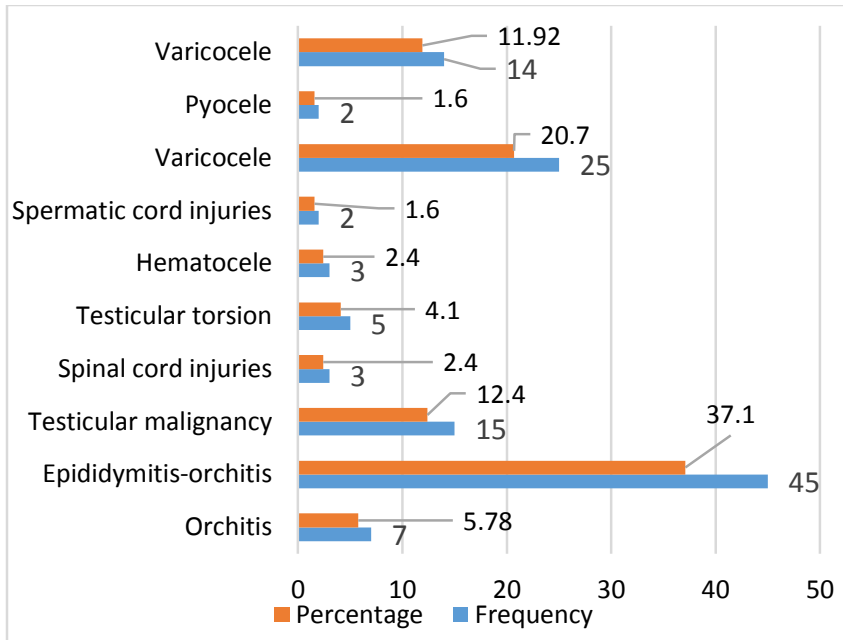

Figure 2. Frequency of Scrotal masses

\section{DISCUSSION}

Scrotal diseases can be diagnosed with a well-established radiological modality known as Doppler ultrasonography. However, due to lack of specificity of conventional ultrasonography in parenchymal changes is the major limitation. Ultrasonography alone cannot differentiate malignant and benign lesions [17]. Furthermore, in acute scrotum epididymal-orchitis cannot be accurately distinguished from the torsional testicular with the help of grayscale ultrasonography. Another study conducted on five patients found normal flow of blood on the opposite side compared to symptomatic side intra testicular blood flow. However, non-specific findings were in the subject, and abnormalities were not found in 3 subjects [18].

Conventional ultrasonography has many drawbacks compared to Doppler ultrasonography. Doppler ultrasonography detects testicular ischemia with nonspecific changes on the grey scale along with testicular arteries. Blood flow can be seen in it. Acute scrotal cases have been accurately diagnosed till now with the help of radionuclide scanning being an important modality. It gives scrotal blood flow information but cannot depict its anatomy $[19,20]$. Currently, acute scrotal pain was assessed and evaluated in patients by Doppler ultrasonography scintigraphy while all the subjects were diagnosed correctly. Scintigraphy failed to diagnose any patient [20]. DUS was a more reliable, safe, non-invasive, and accurate modality compared to scintigraphy [21]. Similar signs and symptoms among the participants made it difficult to clinically diagnose with accuracy. Scrotal pathologies are currently diagnosed with an important imaging modality known as Doppler ultrasonography which allows evaluation of normal anatomy and scrotal condition. Testicular torsion was diagnosed with a specificity of $98.3 \%$ and sensitivity of $90.5 \%$ concluded by another study [22].

Another study found Doppler ultrasonography $100 \%$ specific and sensitive in acute scrotal diagnoses [23]. In our study, orchitis (7),epididymitis-orchitis (45), testicular malignancy (15), spinal cord injuries (3), testicular torsion (5), hematocele (3), spermatic cord injuries(2), varicocele (14), hydrocele (25), and pyocele (2). Out of 15 testicular subjects diagnosed on DUS, only 14 were found to have malignancy. Orchitis' two cases were diagnosed falsely as a malignancy. In Orchitis 7 patients, 6 were diagnosed as orchitis but one had seminoma (specificity 67\% and sensitivity $88 \%$ ). Doppler ultrasonography presented100\% efficiency in terms of specificity and sensitivity while diagnosing testicular torsion and scrotal inflammatory diseases which almost matched our study observations. Other radiological modality such as magnetic resonance imaging can be an effective diagnostic technique for scrotal swelling in case Doppler ultrasonography fails to give satisfactory results. Nuclear scintigraphy, which has a high sensitivity and specificity in distinguishing ischemia from infarction, cannot distinguish ischemia from conditions such as hydrocele, spermatocele, and inguinal hernia and is uncommon due to CDUS's high accuracy [24]. Scrotal disease diagnoses especially in emergency medical settings can be carried out with higher specificity and sensitivity of Doppler ultrasonography.

\section{CONCLUSION}

Our study concluded that perfusion and scrotal anatomy display can be simultaneously diagnosed with DUS as an effective, reliable, and safe imaging modality in scrotal disease (acute or chronic) patients. Patient's management gets better with DUS due to the prevention of unneeded surgical procedures and ease to conduct. DUS has certain limitations such as intratesticular flow detection in children requiring experience and adequate expertise which make it difficult to diagnose.

\section{REFERENCES}

1. Naeem MA, Bacha R, ul Hasan Z, Gilani SA, Farooq SY. Diagnostic Accuracy of Color Doppler \& Grey Scale Ultrasonography in the Diagnosis of Painful Scrotal Conditions. Ophthalmology Update. 2021 Jun 14;19(3):192-6.

2. Feher AM, Bajory Z. A review of main controversial aspects of acute testicular torsion. Journal of Acute Disease 2016; 5:1-8.

3. Selim YARM, Albroumi SA. Acute torsion of the testis in children and young adults: Role of high resolution and Color Doppler ultrasonography. The Egyptian Journal of Radiology and Nuclear Medicine 2015; 46:151-157

4. Boettcher M, Bergholz R, Krebs TF, et al. Differentiation of epididymitis and appendix testis torsion by clinical and ultrasound signs in children. Urology 2013; 82:899-904.

5. Boettcher M, Bergholz R, Krebs TF, et al. Differentiation of epididymitis and appendix testis torsion by clinical and ultrasound signs in children. Urology. 2013;82(4):899-904

6. Rajeswari B. Study on Acute Scrotum: Stanley Medical College, Chennai; 2013.

7. Fabiani A, Calabrese M, Filosa A, Fioretti $F$, Maurelli V, Scandola M, et al. Explorative surgery for acute scrotal pain: the importance of patient age, side affected, time to surgery and surgeon. Arch Ital Urol Androl 2016;88(3):189.

8. Dias Filho AC, Oliveira Rodrigues R, Riccetto CL, Oliveira PG. Improving organ salvage in testicular torsion: comparative study between patients submitted or not to preoperative manual detorsion. J Urol 2017;197(3 Pt 1):811.

9. Saxena AK, Castellani C, Ruttenstock EM, Ho"llwarth ME. Testicular torsion: a 15-year single-centre clinical and histological analysis. Acta Paediatr 2012;101(7):e282.

10. Rosenfield D, Kwan C, Fischer J. Point-of-care ultrasound: an emerging technology in Canadian paediatrics. Paediatr Child Health 2015;20(2):67e8.

11. ] Altinkilic B, Pilatz A, Weidner W. Detection of normal intratesticular perfusion using color coded duplex 
sonography obviates need for scrotal exploration in patients with suspected testicular torsion. J Urol 2013;189(5):1853.

12. Kalfa N, Veyrac C, Lopez M, Lopez C, Maurel A, Kaselas C. Multicenter assessment of ultrasound of the spermatic cord in children with acute scrotum. J Urol 2007;177(1):297.

13. Marin JR, Lewiss RE, American Academy of Pediatrics, Committee on Pediatric Emergency Medicine, et al. Point-ofcare ultrasonography by pediatric emergency medicine physicians. Pediatrics 2015;135(4):e1113.

14. Pereda MA, Chavez MA, Hooper Miele CC, Gilman RH, Steinhoff MC, Ellington LE, et al. Lung ultrasound for the diagnosis of pneumonia in children, a meta analysis. Pediatrics 2015;135(4):714.

15. Sivitz AB, Lam SH, Ramirez Schrempp D, Valente JH, Nagdev AD. Effect of bedside ultrasound on management of pediatric soft tissue infection. J Emerg Med 2010;39(5):637.

16. Riera A, Hsiao AL, Langhan ML, Goodman TR, Chen L. Diagnosis of intussusception by physician novice sonographers in the emergency department. Ann Emerg Med 2012;60(3):264.

17. Pershad J, Myers S, Plouman C, Rosson C, Elam K, Wan J, et al. Bedside limited echocardiography by the emergency physician is accurate during evaluation of the critically ill patient. Pediatrics 2004;114:e667.

18. Elikashvili I, Tay ET, Tsung JW. The effect of point of care ultrasonography on emergency department length of stay and computed tomography utilization in children with suspected appendicitis. Acad Emerg Med 2014;21:163.
19. Harel-Sterling M, Diallo M, Santhirakumaran S, Maxim T, Tessaro M. Emergency Department resource use in pediatric pneumonia: point-of-care lung ultrasonography versus chest radiography. J Ultrasound Med 2019;38(2):407.

20. Blaivas $M$, Sierzenski $P$, Plecque D, Lambert M. Do emergency physicians save time when locating a live intrauterine pregnancy with bedside ultrasonography? Acad Emerg Med 2000;7: 988.

21. Witt M, Baumann BM, McCans K. Bladder ultrasound increases catheterization success in pediatric patients. Acad Emerg Med 2005;12:371.

22. Neal JT, Kaplan SL, Woodford AL, Desai K, Zorc JJ, Chen AE. The effect of bedside ultrasonographic skin marking on infant lumbar puncture success: a randomized controlled trial. Ann Emerg Med 2017;69(5):610.

23. Menaker J, Blumberg S, Wisner DH, Page PS, Dayan M, Tunik $M$, et al. Use of the focused assessment with sonography for trauma (FAST) examination and its impact on abdominal computed tomography use in hemodynamically stable children with blunt torso trauma. J Trauma Acute Care Surg 2014; 77(3):427.

24. Chan EP, Wang PZT, Myslik F, Chen H, Dave S. Identifying systems delays in assessment, diagnosis, and operative management for testicular torsion in a single-payer healthcare system. J Pediatr Urol. Mar 2019;29(19):30074e9. https: //doi.org/10.1016/j.jpurol.2019.03.017. pii: S14775131. 